\title{
Birth preparedness as a precursor to reduce maternal morbidity and mortality among pregnant mothers in Medebay Zana District, Northern Ethiopia
}

\author{
Hailay Gebreyesus ${ }^{1 *}$, Tesfay Berhe ${ }^{1}$ and Mebrahtu Teweldemedhin ${ }^{2}$
}

\begin{abstract}
Objectives: Most maternal and newborn deaths occur during labour and delivery. Birth preparedness and complication readiness practice getting early services when problems may arise is the most achievable components of safe motherhood strategies. However, there is limited evidence found particularly in the study area. Thus, a community based cross-sectional study was conducted from May 17 to June 30, 2017, to assess birth preparedness practice and associated factors among pregnant women in Medebay Zana district in Northern Ethiopia.

Result: The finding showed that about 176 (32\%) of the respondents were prepared for birth based on the criteria set in this study. Preparation for birth was higher among married women ( $\mathrm{OOR}=4.14,95 \% \mathrm{Cl}(1.47-11.64)$ ), among governmental employed women $(\mathrm{AOR}=2.69,95 \% \mathrm{Cl}(1.19-6.05))$, those who attend antenatal care service (AOR, 0.11, $95 \% \mathrm{Cl}(0.05-0.22))$, planned pregnancy $(\mathrm{AOR}=0.06,95 \% \mathrm{Cl}(0.03-0.15)$, those who had saving habit $(\mathrm{AOR}=15.81$, $95 \% \mathrm{Cl}(7.20-34.72)$, duration of pregnancy near to 9 month ( $A O R=5.86,95 \% \mathrm{Cl}(3.25-10.58)$. Preparation for birth was lower among illiterate mothers $(\mathrm{AOR}=0.15,95 \% \mathrm{Cl}(0.07-0.30)$, among mothers who attended primary education $(\mathrm{AOR}=0.01,95 \% \mathrm{Cl}(0.01-0.04))$. The prevalence of birth preparedness practice in the study area was low. Community-based health education about preparation for birth is important.
\end{abstract}

Keywords: Birth preparedness, Pregnant women, North Eastern, Ethiopia

\section{Introduction}

Most of the time pregnancy and childbirth are times of joy for parents, families, and communities at large $[1,2]$. But in many countries where healthcare service coverage and quality remain low, they could also be periods of great risk to the health and survival of women and newborns $[3,4]$.

Globally, around 1500 women die every day from complications related to pregnancy and childbirth [1, $5-7]$. Developing countries account for $99 \%$ of the global maternal deaths and the great share $(62 \%)$ belongs to the sub-Saharan Africa region. Almost $80 \%$ of maternal

\footnotetext{
*Correspondence: ghailay2015@gmail.com

1 Department of Public Health, College of Health Science, Aksum University, P.O. Box 298, Aksum, Ethiopia

Full list of author information is available at the end of the article
}

morbidity and mortality worldwide are directly related to pregnancy and childbirth complications [8]. Obstetric related complications including severe hemorrhage, infection, hypertensive disorders, sepsis and obstructed labor, and unsafe abortion are among the key factors to maternal death [8]. An estimated 125,000 women and 870,000 newborns die every year in Africa, particularly in the 1st week after birth [9]. Ethiopia is one of six countries sharing $50 \%$ of the total global burden of maternal mortality [10]. One of the reasons is the lack of birth preparedness and complication readiness, which is recognized as the most cost-effective and achievable components of safe motherhood programs around the world $[11,12]$.

Birth preparedness and complication are an inclusive strategy aimed to promote timely use or access to skilled maternal and neonatal health services during childbirth 
or obstetric emergencies. It reduces any types of delay through early preparation and decision-making, identifying a skilled birth attendant, support in the family, saving money ad means of transportation, identifying health facility and identification of compatible blood donors when needed [12,13]. Preparedness and complication have been associated with reduced maternal and newborn morbidity and mortality through increased preventive behaviors of mothers and families [14-21].

Even though, the government of Ethiopia has introduced and is currently implementing a policy that provides free maternal healthcare services to all pregnant women and new babies in all governmental healthcare facilities but different studies conducted in Ethiopia showed that birth preparedness and complication readiness among pregnant women was still very low $(22 \%$ and $17 \%)[19,22]$. However, there are no studies which documented birth preparedness and complication readiness practice among pregnant women in the study area. Thus, the aimed of this was to assess the magnitude and associated factors of birth preparedness practice among pregnant women.

\section{Main text \\ Methods \\ Study design and setting}

A community-based cross-sectional study was carried out from May 17 to June 30, 2017, in Medebay Zana district. Medebay Zana is one of the administrative districts of North West Zone of Tigray region, located about $1057 \mathrm{~km}$ away from Addis Ababa. It has 20 smallest Administrative Unit, 7 health centers, and 22 health posts. According to the district health office report in January 2017, the district has an estimated population of 147,822 . The proportion of pregnant women constitutes $3.4 \%$ of the total population that is 5026 .

All pregnant women within the district and all sampled pregnant women within the selected households of the kebeles were the sources and the study population respectively. All self-reporting pregnant mothers who lived in the selected Kebele for at least 6 months were included and those who are unable to give appropriate responses due to their physical and mental illness were excluded from the study.

\section{Sample size and sampling techniques}

The sample size was determined by using a single population proportion formula using the following assumption: Proportion of pregnant women who were prepared for birth/have birth plan (p) 17\% of birth preparedness practice among pregnant women in southern Ethiopia [11], margin of error $(d)=3 \%$ and $95 \%$ confidence level and $5 \%$ for possible non response rate. So the final sample size was 552.

From the 20 kebeles of the district, 6 were randomly selected; the sample was taken from selected kebeles proportional to population size and then a simple random sampling technique was used to select study participants within each kebele. List of pregnant mothers with their household numbers was taken from community health information system registration prepared by health extension workers as the sampling frame then independent sampling frame was developed for each kebele. The data collection was continuous until the predetermined sample size obtained.

\section{Operational definitions}

Birth preparedness practice The pregnant woman was asked whether she followed the desired elements of birth preparedness practice. Which consists of 4 items, the responses were scored as " 0 " for no answer and " 1 " for yes answer. And the total score was obtained by computing all items, which range from 0 to 4 points. Respondents scores $\geq 3$ was considered as being well-prepared and the rest as not well prepared for birth.

If pregnant mother she can mention at least three of the key four danger signs during labour/childbirth (severe vaginal bleeding, prolonged labour $(>12 \mathrm{~h})$, convulsion and retained placenta) spontaneously, she was considered as knowledgeable otherwise not knowledgeable.

If she can mention at least two of the three key danger signs during pregnancy (vaginal bleeding, swollen hands/ face, and blurred vision) spontaneously, she was considered as knowledgeable otherwise not knowledgeable [22, 23].

Data collection tool The data collection tool was adopted from the safe motherhood questionnaire developed by maternal and neonatal health program of JHPIEGO the affiliate of Johns Hopkins University according to the context and objectives of the study [12]. The questionnaire was prepared in English and translated to local language (Tigrigna) and translated back to English by another translator. Five \% of the questionnaire was pre-tested in a similar setting; correction and modification were done based on the gap identified during the interview. The questionnaire was grouped into four categories; Sociodemographic characteristics; health service utilization factors; obstetric characteristic and Knowledge on danger signs of pregnancy, labor, and delivery.

\section{Data collection technique and quality control}

Data were collected by four clinical nurses using a pretested structured questionnaire and supervised by two general public health experts and the principal 
investigator. Training was given for 2 consecutive days on the aim of the research, content of the questionnaire and how to conduct the interview for data collectors and supervisors to increase their performance in field activities. Strict supervision was done by supervisors and principal investigators.

Data processing and analysis The data were checked and edited, then coded, entered into EPI Info version 7.1.2 and exported to SPSS Version 21 for analysis, cleaned and checked for outliers and completeness. Frequency, percentages, proportions, odds ratios, and logistic regressions were computed. Variables with a $\mathrm{P}<0.05$ and AORs with the $95 \%$ confidence interval were considered as significant.

\section{Result}

\section{Socio-demographic characteristics}

In this study, a total of 552 pregnant women were interviewed. All eligible pregnant women selected in the samples responded to the questionnaire. The mean age of the participants was 26.9 (SD of 6.9) years. Majority of the pregnant women $488(88.4 \%)$ were married and 121 (21.9) pregnant women were unable to read and write (Table 1).

\section{Antenatal care visits during the current pregnancy}

About 450 (81.5\%) planned their pregnancy and 376 (68.1\%) attended ANC checkup; only 218 (58\%) of the pregnant women attended ANC 4 or more times during their current pregnancy. Half of them 276 (84.4\%) got advice on birth preparation during their ANC visit (Additional file 1: Table S1).

\section{Obstetric characteristics of the respondents related to their previous pregnancy}

Two hundred seventy-one $(49.1 \%)$ of the respondents were pregnant for the first time. Majority of them (79.4\%) were gravid 1-2 and five (1.8\%) of the pregnant women had a history of stillbirth (Additional file 2: Table S2).

\section{Birth preparedness practices}

Out of the 552 pregnant women, 176 (32\%) were considered as being well prepared to give birth. Three hundred thirty-five $(60.7 \%)$ respondents reported that they saved money, 179 (32.4\%) identified means of transportation, $371(67.2 \%)$ identified their place of delivery and 173 (31.3\%) mothers had already identified skilled birth attendant (Table 2).

\section{Factors associated with birth preparedness practices}

In the multiple variable logistic regression analysis, marital status, educational status, planned pregnancy, ANC
Table 1 Socio-economic and demographic characteristics among pregnant women in Medebay Zana district, July 2017

\begin{tabular}{|c|c|c|}
\hline Variables & Category & N (\%) \\
\hline \multirow[t]{5}{*}{ Age } & $\leq 20$ & $118(21.4)$ \\
\hline & $21-25$ & $136(24.6)$ \\
\hline & $26-30$ & $154(27.9)$ \\
\hline & $31-35$ & $48(8.7)$ \\
\hline & $>35$ & $96(17.4)$ \\
\hline \multirow[t]{2}{*}{ Religion } & Orthodox & $523(94.7)$ \\
\hline & Muslim & $29(5.3)$ \\
\hline \multirow[t]{2}{*}{ Ethnicity } & Tigrean & $532(96.4)$ \\
\hline & Others $^{a}$ & $20(3.6)$ \\
\hline \multirow[t]{2}{*}{ Marital status } & Married & $488(88.4)$ \\
\hline & Not married & $64(11.6)$ \\
\hline \multirow[t]{3}{*}{ Educational level } & Illiterate & 302 (54.7.) \\
\hline & Primary education & $137(24.8)$ \\
\hline & Secondary and above education & $113(20.5)$ \\
\hline \multirow[t]{4}{*}{ Occupation } & Housewife & $347(62.9)$ \\
\hline & Governmental employed & $77(13.9)$ \\
\hline & Merchant & $73(13.2)$ \\
\hline & Others $^{b}$ & $55(10.0)$ \\
\hline \multirow[t]{3}{*}{ Monthly family income } & $<650$ Birr & $208(37.7)$ \\
\hline & 651-1500 Birr & $182(33.0)$ \\
\hline & $>1500$ Birr & $162(29.3)$ \\
\hline \multirow[t]{3}{*}{ Family size } & $0-2$ & $420(76.1)$ \\
\hline & $3-4$ & $90(16.3)$ \\
\hline & $\geq 5$ & $42(7.6)$ \\
\hline
\end{tabular}

a Amhara, Afar and Yem

b Daily laborers and privet employed

care, saving habit and duration of pregnancy remained significantly associated with birth preparedness practice. Those women who were in marital union were 4.14 times more likely to be prepared for birth than those who were not in marital union $(\mathrm{AOR}=4.14,95 \% \mathrm{CI}(1.47-$ 11.64)). Those illiterate pregnant women were 6.67 times less likely to be prepared for birth than those who were attended secondary and above education $(\mathrm{AOR}=0.15$, 95\% CI (0.07-0.30)) and pregnant women who attended primary education were 100 times less likely to be prepared for birth than those who were attended secondary and above education (AOR $=0.01,95 \% \mathrm{CI}(0.01-0.04)$ ). Mothers who were not planned to their pregnancy were 16.67 times less likely to practice birth preparedness when compared to those who had planned pregnancy $(\mathrm{AOR}=0.06,95 \% \mathrm{CI}(0.03-0.15))$. Mothers who had saving habit for their labor and delivery were 15.81 times more likely to be prepared for birth (AOR, 15.81, 95\% CI (7.20-34.72)). Pregnant women who were attended ANC follow up for their pregnancy were 9.09 times more likely 
Table 2 Practices of respondents on preparation for birth with current pregnancy among pregnant women in Medebay Zana district, July 2017

\begin{tabular}{llc}
\hline Variables & Category & N (\%) \\
\hline Saved habit & Yes & $335(60.7)$ \\
Arranged transport & No & $217(39.3)$ \\
& Yes & $179(32.4)$ \\
Identified a skilled birth attendant & Yes & $373(67.6)$ \\
Identified facility for delivery & No & $173(31.3)$ \\
& Yes & $379(68.7)$ \\
Place of delivery & No & $371(67.2)$ \\
Final decision maker on birth place & Bealth institution & $293(79)$ \\
& Other place & $78(21)$ \\
& Women & $261(47.3)$ \\
\hline
\end{tabular}

${ }^{\text {a }}$ Home or out any health institutions

to be prepared for birth (AOR, 9.09, 95\% CI (0.05-0.22)). Pregnant women who were their pregnancy duration 7-9 months were 5.86 times more likely to practice birth preparedness as compared to those who were their pregnancy duration 3-6 months $(\mathrm{AOR}=5.86,95 \% \mathrm{CI}(3.25-$ 10.58)) (Table 3).

\section{Discussion}

This community based cross-sectional study assessed the magnitude and factors associated with birth preparedness. The proportion of birth preparedness practice was found to be $32 \%$. This finding is higher than the figures of other study conducted in Ethiopia [11, 22] but lower than that of Nigeria [24] and India [17]. This could be due to the socio-economic status of the participants and or access to health facility.

In this study, marital status, educational status, planned pregnancy, ANC care, saving habit, and duration of pregnancy were significantly associated with birth preparedness. Married women were more likely to be prepared for birth than those who were not married. This could be because; married women may have supported by their husbands to prepared and utilized maternal healthcare. Similar findings have been observed in the studies conducted in Tanzania, Uganda, North Ethiopia and Indore city of India [17, 20, 22, 25]. This might be due to husband's knowledge and awareness towards birth preparedness.

Mothers' occupational status was significantly associated with birth preparedness in this study. Those pregnant women who were governmental employed, merchants and others (daily laborers and privet employed) in their occupational status were more likely to be prepared for birth than those who were housewife. Similar finding was found in a study done in Ethiopia and India $[17,22]$. Pregnant women with planned pregnancy were more likely to be prepared for birth than those with an unintended pregnancy. Those mothers with planned pregnancy already accepted it and try their best to get prepared for birth. Those pregnant women who attended ANC were found to be more likely to be prepared for birth. ANC is important to offer advice and information about birth preparedness, danger signs of obstetric complications and emergency preparedness. Birth preparedness is a basic element of ANC aimed to reduce and unnecessary delays and hence improves maternal and fetal outcomes [12]. Additionally, any visit to a health facility was significantly associated with birth preparedness in some other studies [11,20,22, 26]. The current study also identified pregnant women who had saving habit during their pregnancy. The results showed that about $53.5 \%$ of the respondents had saving habit during their current pregnancy by saving money, identifying a means of transportation and identifying skilled personnel. Transportation is a barrier to reach the health facilities and seek care; it could be difficult to secure transport after labor has already occurred. Saving money and arranging transport ahead of time reduces the delay in reaching the appropriate place where service is given. In this study, more than half of the respondents had saving habit and have identified a means of transportation ahead of time which is higher as compared to a study conducted in Ethiopia [11]. In this study duration of pregnancy was significantly associated with birth preparedness. Those mothers who were clothed their pregnancy duration to 9 month was more likely to be prepared for birth as compared to those who were not clothed their pregnancy duration 9 month (AOR $=5.86,95 \%$ CI $(3.25-10.58)$. this finding is similar with previous studies in Ethiopia [11, $16]$.

In this study $1.8 \%$ of the pregnant women had a stillbirth which is lower as compared to previous studies conducted in Ethiopia which was 9.3 and 5.9\% respectively $[16,27]$. In general, the magnitude of birth preparedness practice is low in the study area. Marital status, educational status, planned pregnancy, ANC follow up, saving habit and duration of pregnancy were factors associated with birth preparedness practice. Thus, sustainable and comprehensive community-based education about preparation for birth and empowerment of women by expanding educational opportunities are important factors in enhancing birth preparedness. 
Table 3 Factors associated with birth preparedness practices among pregnant women in Medebay Zana district, July 2017

\begin{tabular}{|c|c|c|c|c|}
\hline \multirow[t]{2}{*}{ Variables } & \multicolumn{2}{|c|}{ Birth preparedness practice } & \multirow[t]{2}{*}{ COR $(95 \% \mathrm{Cl})$} & \multirow[t]{2}{*}{ AOR $(95 \% \mathrm{Cl})$} \\
\hline & No n (\%) & Yes n (\%) & & \\
\hline \multicolumn{5}{|l|}{ Marital status } \\
\hline In marital union & $321(65.8)$ & $167(34.2)$ & $3.12(1.53-6.60)^{*}$ & $4.14(1.47-11.64)^{*}$ \\
\hline Not in marital union & $55(85.9)$ & $9(14.1)$ & 1 & 1 \\
\hline \multicolumn{5}{|l|}{ Educational status } \\
\hline Illiterate & $217(71.6)$ & $86(28.4)$ & $0.16(0.10-0.25)^{*}$ & $0.15(0.07-0.30)^{*}$ \\
\hline Primary & $127(93.4)$ & $9(6.6)$ & $0.03(0.01-0.06)^{*}$ & $0.01(0.01-0.04)^{*}$ \\
\hline Secondary and above & $32(28.3)$ & $81(71.7)$ & 1 & 1 \\
\hline \multicolumn{5}{|l|}{ Occupation } \\
\hline House wife & $285(82.1)$ & $62(17.9)$ & 1 & 1 \\
\hline Governmental employed & $39(50.6)$ & $38(49.4)$ & $4.46(2.47-7.57)^{*}$ & $2.69(1.19-6.05)^{*}$ \\
\hline Merchant & $27(37.0)$ & $46(63.0)$ & $7.83(4.52-13.56)^{*}$ & $4.02(1.73-9.37)^{*}$ \\
\hline Others & $25(45.5)$ & $30(54.5)$ & $5.52(3.04-10.03)$ & $5.27(2.17-12.80)^{*}$ \\
\hline \multicolumn{5}{|l|}{ Planned pregnancy } \\
\hline Yes & $250(66.5)$ & $126(33.5)$ & 1 & 1 \\
\hline No & $126(71.6)$ & $50(28.4)$ & $1.31(0.86-1.88)$ & $0.06(0.03-0.15)^{*}$ \\
\hline \multicolumn{5}{|l|}{ ANC care } \\
\hline Yes & $181(58.8)$ & $127(41.2)$ & $2.79(1.89-4.11)^{*}$ & $0.11(0.05-0.22)^{*}$ \\
\hline No & $195(79.9)$ & $49(20.1)$ & 1 & 1 \\
\hline \multicolumn{5}{|l|}{ Saving habit } \\
\hline Yes & $101(46.5)$ & $116(53.5)$ & $5.26(3.56-7.75$ & $15.81(7.20-34.72)^{*}$ \\
\hline No & $275(82.1)$ & $60(17.9)$ & 1 & 1 \\
\hline \multicolumn{5}{|l|}{ Arranged transport } \\
\hline Yes & $127(70.9)$ & $52(29.1)$ & $1.22(.82-1.79)$ & 1 \\
\hline No & $249(66.8)$ & $124(33.2)$ & 1 & \\
\hline \multicolumn{5}{|l|}{ First pregnancy } \\
\hline Yes & $220(81.2)$ & $51(18.8)$ & 1 & 1 \\
\hline No & $156(55.5)$ & $125(44.5)$ & $3.46(2.35-5.08)^{*}$ & $1.22(0.63-2.35)$ \\
\hline \multicolumn{5}{|c|}{ Duration of pregnancy (months) } \\
\hline $3-6$ & $101(51.0)$ & $97(49.0)$ & $3.34(2.30-4.86)$ & 1 \\
\hline $7-9$ & $275(77.7)$ & $79(22.30)$ & 1 & $5.86(3.25-10.58)^{*}$ \\
\hline \multicolumn{5}{|c|}{ Knows danger signs of labor and delivery } \\
\hline Yes & $197(91.6)$ & $6(4.6)$ & 1 & \\
\hline No & $124(95.4)$ & $18(8.4)$ & $1.89(0.73-4.89)$ & $0.76(0.15-3.96)$ \\
\hline
\end{tabular}

ANC antenatal care, $A O R$ adjusted odds ratio, $\mathrm{Cl}$ confidence interval, $C O R$ crude odds ratio

1: referent

* Significant at $p$ value $<0.05$

\section{Limitation of the study}

As it was a cross-sectional study, causality may not be established and since the participants have not completed their period of pregnancy, they may have the opportunity or need to make arrangements related to birth preparedness practice than the currently reported prevalence may underestimate the real prevalence on the ground.

\section{Additional files}

Additional file 1: Table S1. Antenatal care services and awareness on obstetric danger signs among pregnant women in Medebay Zana district, July 2017.

Additional file 2: Table S2. Obstetric characteristics related to the previous pregnancy among pregnant women in Medebay Zana district, July 2017. 


\section{Abbreviations}

ANC: antenatal care; BP: birth preparedness; DHS: demographic and health survey; HEW: health extension worker; TBA: traditional birth attendants; TTBA: trained traditional birth attendants; SPSS: Statistical Package for Social Science; USA: United State of America; WHO: World Health Organization.

\section{Acknowledgements}

Our heartfelt thank goes to Aksum University for financial support. We are thankful to Medebay Zana district health office for their positive responses to facilitate the study and all study participants who voluntarily participated in this study.

\section{Authors' contributions}

HG wrote the proposal, participated in data collection, analyzed the data, and drafted the paper. TB and MT approved the proposal, participated in data analysis and revised subsequent drafts of the paper. All authors read and approved the final manuscript.

\section{Funding}

This work was funded by Aksum University. The funder financed the process of data collection, analysis and interpretation of the data.

\section{Availability of data and materials}

The datasets in which conclusion taken is available in the form of Microsoft Excel. It is available on requesting.

\section{Ethical approval and consent to participate}

The study was approved by the Research Ethics Committee of Aksum University, College of Health science and permission letter was also obtained from Medebay Zana district health office and was presented to all participants. Written consent was obtained from all participants. Confidentiality and privacy of the study were maintained during data collection, analysis, and reporting by making the questionnaire anonymous.

\section{Consent for publication}

Not applicable.

\section{Competing interests}

The authors declare that they have no competing interests.

\section{Author details}

${ }^{1}$ Department of Public Health, College of Health Science, Aksum University, P.O. Box 298, Aksum, Ethiopia. ${ }^{2}$ Department of Medical Laboratory Science, College of Health Sciences, Aksum University, Aksum, Ethiopia.

Received: 25 January 2019 Accepted: 22 May 2019

Published online: 28 May 2019

\section{References}

1. UNICEF, WHO, the World Bank, United Nations Population Division. The inter-agency group for child mortality estimation (UN IGME): levels and trends in child mortality. New York: UNICEF; 2013.

2. WHO, UNICEF, UNFPA, the World Bank. Trends in maternal mortality: 2010 Geneva: UN Inter-agency Group for Maternal Mortality Estimation (UNIGMME): 2012.

3. Filippi V, Ronsmans C, Campbell OM, Graham WJ, Mills A, Borghi J, et al. Maternal health in poor countries: the broader context and a call for action. Lancet. 2006;368(9546):1535-41.

4. Alkema L, Chou D, Hogan D, United Nations Maternal Mortality Estimation Inter-Agency Group collaborators and technical advisory group, et al. Global, regional, and national levels and trends in maternal mortality between 1990 and 2015, with scenario-based projections to 2030: a systematic analysis by the UN Maternal Mortality Estimation Inter-Agency Group. Lancet. 2016:387:462-74

5. Lawn JE, Cousens S, Zupan J, Team LNSS. 4 million neonatal deaths: when? where? why? Lancet. 2005;365(9462):891-900.

6. Ronsmans C, Graham WJ, group LMSSs. Maternal mortality: who, when, where, and why. Lancet. 2006;368(9542):1189-200.
7. Stanton C, Lawn JE, Rahman H, Wilczynska-Ketende K, Hill K. Stillbirth rates: delivering estimates in 190 countries. Lancet. 2006;367(9521):1487-94.

8. UNICEF. Trends in maternal mortality: 1990 to 2013. New York: UNICEF; 2014.

9. Warren C, Daly P, Toure L, Mongi P. Postnatal care. Opportunities for Africa's newborns Cape Town, South Africa: partnership for maternal, newborn and child health. WHO: New York; 2006. p. 79-90.

10. Health FMo, Directorate EHANRIEHSR. Baseline evaluation of maternal and newborn health care services in 25 selected woredas.

11. Hailu M, Gebremariam A, Alemseged F, et al. Birth preparedness and complication readiness among pregnant women in southern Ethiopia. PLOS ONE. 2011;6:e21432.

12. JHPIEGO/Maternal and Neonatal Health Program. Birth preparedness and complication readiness: a matrix of shared responsibility. Baltimore: Jhpiego Maternal and Neonatal Health Program; 2001.

13. Mutiso SM, Qureshi Z, Kinuthia J. Birth preparedness among antenatal clients. East Afr Med J. 2008;85(6):275-83.

14. Markos D, Bogale D. Birth preparedness and complication readiness among women of the childbearing age group in Goba woreda, Oromia region, Ethiopia. BMC Pregnancy Childbirth. 2014;14(1):282.

15. Manandhar DS, Osrin D, Shrestha BP, Members of the MIRA Makwanpur trial team, et al. Effect of a participatory intervention with women's groups on birth outcomes in Nepal: cluster-randomised controlled trial. Lancet. 2004:364:970-9.

16. Belda SS, Gebremariam M. Birth preparedness, complication readiness and other determinants of place of delivery among mothers in Goba District, bale zone, south East Ethiopia. BMC Pregnancy Childbirth. 2016;16:73.

17. Agarwal S, Sethi V, Srivastava K, et al. Birth preparedness and complication readiness among slum women in Indore City, India. J Health Popul Nutr. 2010;28:383-91.

18. Urassa DP, Pembe AB, Mganga F. Birth preparedness and complication readiness among women in Mpwapwa district, Tanzania. Tanzania J Health Res. 2013;14:42-7.

19. Gebre M, Gebremariam A, Abebe TA. Birth preparedness and complication readiness among pregnant women in Duguna Fango District, Wolayta Zone, Ethiopia. PLoS ONE. 2015;10(9):e0137570.

20. Bintabara D, Mohamed M, Mghamba J, et al. Birth preparedness and complication readiness among recently delivered women in chamwino district, central Tanzania: a cross sectional study. Reprod Health. 2015:12:44

21. Mushi D, Mpembeni R, Jahn A. Effectiveness of community based safe motherhood promoters in improving the utilization of obstetric care. The case of Mtwara Rural District in Tanzania. BMC Pregnancy Childbirth. 2010:10:14.

22. Hiluf M, Fantahun M. Birth preparedness and complication readiness among women in Adigrat town, north Ethiopia. Ethiop J Health Dev. 2007:22:14-20.

23. Mbalinda SN, Nakimuli A, Kakaire O, Osinde MO, Kakande N, Kaye DK. Does knowledge of danger signs of pregnancy predict birth preparedness? A critique of the evidence from women admitted with pregnancy complications. Health Res Policy Syst. 2014;12(1):60.

24. Ekabua JE, Ekabua KJ, Odusolu P, Agan TU, Iklaki CU, Etokidem AJ. Awareness of birth preparedness and complication readiness in Southeastern Nigeria. ISRN Obstet Gynecol. 2011;2011:560641.

25. Kabakyenga JK, Östergren PO, Turyakira E, Pettersson KO. Knowledge of obstetric danger signs and birth preparedness practices among women in rural Uganda. Reprod Health. 2011;8(1):33.

26. Wiegers TA, Boerma WGW, Haan O. Maternity care and birth preparedness in rural Kyrgyzstan and Tajikistan. Sex Reprod Healthc. 2010;4:189-94.

27. Bitew $Y$, Awoke W, Chekol S. Birth preparedness and complication readiness practice and associated factors among pregnant women, Northwest Ethiopia. Int Sch Res Notices. 2016;2016:8727365.

\section{Publisher's Note}

Springer Nature remains neutral with regard to jurisdictional claims in published maps and institutional affiliations. 